\title{
EFEKTIVITAS TERAPI TOKEN EKONOMI UNTUK MENINGKATKAN KEPATUHAN MENGERJAKAN TUGAS PADA ANAK TAHAP USIA SEKOLAH
}

\author{
Yeni Devita ${ }^{1,}$ Rahmat Mulyadi ${ }^{2}$ \\ ${ }^{1,2}$ Program Studi S1 Keperawatan, Sekolah Tinggi Ilmu Kesehatan Payung Negeri Pekanbaru \\ Email: yenidevita@ payungnegeri.ac.id
}

\begin{abstract}
ABSTRAK
Token ekonomi merupakan salah satu modifikasi perilaku dengan cara memperoleh token ketika mereka mengumpulkan sesuai target yang ditentukan maka token tersebut akan ditukarkan berupa hadiah. Disiplin merupakan sebuah proses pembiasaan yang dilakukan secara berulang dan konsisten, Penanaman disiplin ini dilakukan karna salah satu dasar anak dalam rangka pembentukan dan pengembangan wataknya secara sehat, Tujuan penelitian ini untuk mengetahui efektivitas terapi token ekonomi untuk meningkatan kepatuhan mengerjakan tugas pada anak tahap usia sekolah. Jenis penelitian ini Quasi eksperimen dengan desain Pre-test - Post-tes Whitout control. Sampel terdiri dari 127 siswa. Metode pengambilan sample adalah Purposive Sampling.penelitian ini dimulai dari tanggal 28 mei sampai dengan 04 juni 2018. Analisis yang digunakan adalah paired T-test, Hasil paired t-test didapatan nilai $\mathrm{p}$ value $=0,000$, hal ini berarti nilai $\mathrm{p}<0,05$ sehingga Ho ditolak, artinya ada pengaruh terapi token ekonomi untuk meningkatan kepatuhan mengerjakan tugas pada anak tahap usia sekolah, Rekomendasi penelitian ini adalah terapi token ekonomi dapat diaplikasikan di sekolah untuk menjadikan siswa menjadi disiplin .
\end{abstract}

Kata kunci : Terapi token ekonomi, Disiplin mengerjakan tugas, Anak Sekolah

\section{ABSTRACT}

Economic token is one behavior modification by obtaining a token when they collect according to the specified target then the tokens will be redeemed in the form of a reward. Discipline is a habituation process that is carried out repeatedly and consistently, the planting of this discipline is carried out because one of the basic children in the framework of the formation and development of his character in a healthy manner. This research type Quasi experiment with Pre-test-Post-test design Whitout control. Sample consists of 127 students. The sampling method was purposive sampling. This study started from May 28 to June 4 2018. The analysis used was paired T-test, the results of paired t-test found $p$ value $=0,000$, this means that the value of $p<0$, 05 so Ho is rejected, it means there is influence of economic token therapy to improve adherence to perform tasks at school stage children, the recommendation of this research is economic token therapy for applied at school to make students discipline.

Keywords: Economic token therapy, Discipline work on duty, School Children 


\section{LATAR BELAKANG}

Anak adalah aset bangsa yang merupakan cikal bakal lahirnya generasi penerus harapan perjuangan bangsa, semakin optimalnya pencapaian tugas perkembangan anak maka semakin baik pula kehidupan dan begitu pula sebaiknya (Hurlock, 2009). Anak adalah individu yang berbeda dalam rentang pertumbuhan dan perkembangan yang terjadi secara berkesinambungan dimulai dari fase bayi sampai dengan remaja (Wong, 2009). Tahapan- tahapan tumbuh kembang anak secara garis besar yaitu : Periode pertama adalah masa neonatal dimana bayi berusia 0 28 hari dilanjutkan masa bayi yaitu sampai usia 2 tahun, masa prasekolah usai 3-6 tahun, masa selanjutnya yaitu masa sekolah berusia 6-12 tahun dan berakhir diusia 18 tahun yaitu usia remaja (Wong, 2009).

Pada masa ini anak memasuki masa belajar dalam dan diluar sekolah, dengan memberikan tugas dirumah akan mendukung hasil belajar disekolah. Tugas perkembangan anak sekolah yaitu mempelajari keterampilan fisik yang diperlukan, membentuk sikap yang sehat mengenai dirinya sendiri, mulai mengembangkan peran, memperoleh kebebasan, belajar menyesuaikan diri dengan teman-teman seusianya dan mengembangkan keterampila-keterampilan dasar untuk membaca ,menulis dan berhitung dan mengembangkan sikap terhadap kelompok-kelompok sosial dan lembaga-lembaga (Gunarsa D, 2008).

Untuk mecapai tugas perkembangan optimal pada anak usia sekolah dibutuhkan stimulasi agar tahap perkembangan anak tidak terjadi hambatan, adanya hambatan dalam kemampuan mencapai tugas perkembangannya dapat menyebabkan anak merasa rendah diri dan tak percaya diri (Stuart, 2013). Rasa tidak percaya diri pada anak disebabkan karena anak tidak memiliki strategi koping yang positif untuk berinteraksi dengan orang sekitar (Kingsbury, Coplan, \& Rose Krasnor, 2013). Sehingga anak pada masa dewasa tidak mengalami hambatan dalam bersosialisasi (Stuart, 2013).

Stimulasi perkembangan yang optimal pada anak dapat menghasilkan karakteristik anak yang sehat dan memiliki kemampuan industri yang optimal meliputi berkembangnya aspek motori anak (beraktifitas secara fisik dan mengandalkan otot), anak memiliki rasa bersaing dan bertanding secara sehat dengan teman sebayanya, kemampuan menulis, membaca, dan berhitung meningkat, berpikir realistis, memiliki teman sebaya, mampu mengendalikan emosi, mampu mengenal baik-buruk dan norma-norma yang berlaku dilingkungan sekitar (Stuart, 2013).

Salah satu terapi yang diterapkan dalam stimulasi perkembangan anak usia sekolah agar perkembangan optimal yaitu dengan terapi tingkah laku atau terapi token ekonomi, terapi tingkah laku bertujuan untuk memperoleh tingkah laku baru dan mempertahankan tingkah laku yang diinginkan (Corey, 2013). Token ekonomi merupakan salah satu tehnik modifikasi perilaku dengan cara memperoleh token ketika mereka mengumpulkan sesuai target yang ditentukan maka token tersebut akan ditukarkan berupa hadiah (Martin dan Pear, 2009). Token ekonomi bertujuan mengubah motivasi intrinsik dengan pelaksanaan token ekonomi yang diharapkan bahwa perolehan tingkah laku yang diinginkan dengan sendirinya akan mendapatkan hasil yang positif dan menjadikan tingkah laku yang baru (Martin dan Pear, 2009).

Tujuan dari penelitian ini adalah untuk mengetahui efektivitas terapi token ekonomi untuk meningkatkan kepatuhan mengerjakan tugas pada anak tahap usia sekolah. 


\section{METODE PENELITIAN}

Jenis penelitian ini merupakan penelitian Quasi eksperimen dengan desain Pre-testPost-tes without control. Lokasi penelitian dilakukan di SDN 37 Tampan Pekanbaru pada bulan Januari hingga April 2018. Populasi dalam penelitian ini adalah seluruh siswa kelas IV dengan sampel 127 siswa. Teknik pengambilan sampel dalam penelitian ini adalah metode Purposive Sampling. Analisa Data yang digunakan pada penelitian ini adalah uji paired $t$-test.

\section{HASIL PENELITIAN}

Hasil penelitian berupa analisa univariat dan bivariat yang dapat dilihat sebagai berikut :

\section{A. Hasil Analisa Univariat}

1. Karakteristik Responden

a. Jenis kelamin

Tabel 1

\section{Distribusi Responden Berdasarkan jenis} kelamin

\begin{tabular}{clcc}
\hline No & Jenis Kelamin & n & \% \\
\hline 1 & Laki - Laki & 81 & 63,8 \\
\hline 2 & Perempuan & 46 & 36,2 \\
\hline
\end{tabular}

Berdasarkan hasil analisis data diketahui bahwa, dari 127 responden, distribusi responden menurut jenis kelamin laki-laki sebanyak 81 orang dengan persentase 63,8 $\%$ dan perempuan sebanyak 46 orang dengan persentase $36,2 \%$.

b. Umur

\section{Tabel 2}

Distribusi Responden Berdasarkan Umur

\begin{tabular}{|c|c|c|c|c|c|c|}
\hline $\mathbf{n}$ & Mean & Median & SD & SE & Min & Max \\
\hline 127 & 10,57 & 11 & 0,044 & 0,496 & 10 & 11 \\
\hline
\end{tabular}

Berdasarkan hasil analisis data diketahui bahwa rata-rata umur responden adalah 10,57 dengan umur termuda 10 tahun dan tertua 11 tahun. c. Kepatuhan Mengerjakan Tugas Sebelum Diberikan Terapi Token Ekonomi

Tabel 3

Kepatuhan Mengerjakan Tugas Sebelum Diberikan Terapi Token Ekonomi

\begin{tabular}{|c|c|c|c|c|c|c|}
\hline $\mathbf{n}$ & Mean & Median & SD & SE & Min & Max \\
\hline 127 & 2,78 & 2,00 & 2,403 & 0,213 & 0 & 8 \\
\hline
\end{tabular}

Berdasarkan hasil analisis data diketahui bahwa rata-rata kepatuhan mengerjakan tugas sebelum diberikan terapi token ekonomi adalah 2,78 dengan nilai minimum 0 dan maksimum 8 tugas yang dikumpulkan.

d. Kepatuhan Mengerjakan Tugas Setelah Diberikan Terapi Token Ekonomi

Tabel 4

Kepatuhan Mengerjakan Tugas Setelah Diberikan Terapi Token Ekonomi

\begin{tabular}{|c|c|c|c|c|c|c|}
\hline $\mathbf{n}$ & Mean & Median & SD & SE & Min & Max \\
\hline 127 & 6,57 & 6,00 & 1,780 & 0,158 & 3 & 10 \\
\hline
\end{tabular}

Berdasarkan hasil analisis data diketahui bahwa rata-rata kepatuhan mengerjakan tugas sesudah diberikan terapi token ekonomi adalah 6,57 dengan nilai minimum 3 dan maksimum 10 tugas yang dikumpulkan.

\section{B. Hasil Analisa Bivariat Tabel 5}

Efektifitas Terapi Token Ekonomi Untuk Meningkatkan Kepatuhan Mengerjakan Tugas Pada Anak Usia Sekolah

\begin{tabular}{|c|c|c|c|c|}
\hline Perlakuan & Mean & SD & SE & $\begin{array}{c}\text { P } \\
\text { Value }\end{array}$ \\
\hline $\begin{array}{c}\text { Sebelum } \\
\text { Diberikan } \\
\text { Terapi }\end{array}$ & 2,78 & 2,403 & 0,213 & \\
\hline $\begin{array}{c}\text { Setelah } \\
\text { Diberikan } \\
\text { Terapi }\end{array}$ & 6,57 & 1,780 & 0,158 & 0,000 \\
\hline
\end{tabular}


Berdasarkan hasil analisis data diketahui bahwa sebelum diberikan terapi token ekonomi rata-rata kepatuhan mengerjakan tugas hanya 2,78 , namun setelah diberikan terapi token ekonomi rata-rata kepatuhan mengerjakan tugas meningkat menjadi 6,57. Dari hasil uji paired t-test didapatkan $\mathrm{p}$ value nya 0,000 yang artinya terapi token ekonomi efektif dalam meningkatkan kepatuhan pada anak usia sekolah.

\section{PEMBAHASAN}

Berdasarkan hasil penelitian dengan menggunakan uji paired $t$ test diketahui bahwa didapatkan nilai $p$ value yaitu 0,000 lebih kecil dari 0,05 artinya ada pengaruh antara responden sebelum dan sesudah diberikan terapi token ekonomi. Adapun perbedaan untuk sebelum diberikan tugas terapi token ekonomi dengan rata-rata kepatuhan 2,78 dengan nilai minimum 0 dan maksimum 8 tugas yang dikumpulkan dan untuk sesudah diberikan tugas terapi token ekonomi dengan rata-rata 6,57 dengan nilai minimum 3 dan maksimum 10 tugas yang dikumpulkan.

Menurut Mujianti (2015) bahwa penggunaan teknik token ekonomi terbukti efektif untuk merubah tingkah laku agar dalam proses pembelajarannya siswa bisa lebih antusias, hal ini dikarenakan dalam penerapan teknik token ekonomi lebih terfokus pada tingkah laku yang ditujukan pada siswa sesuai targetn yang disepakati dengan menggunakan penguat positif. Token ekonomi bertujuan mengubah motivasi intrinsik dengan pelaksanaan token ekonomi yang diharapkan bahwa perolehan tingkah laku yang diinginkan dengan sendirinya akan mendapatkan hasil yang positif dan menjadikan tingkah laku yang baru (Martin dan Pear, 2009). Hal ini diperkuat oleh Muffidah (2012) dimana dengen kepatuhan mengerjakan tugas untuk mendorong anak memperbaiki kedisiplinan agar meningkatkan belajarnya sehingga mendapatkan sebuah hasil belajar yang baik atau memuaskanyang diperoleh dari proses belajar.

Kepatuhan mengerjakan tugas atau disiplin mengerjakan tugas merupakan sebuah sikap yang harus dibentuk dan tidak dapat terjadi dengan sendirinya. Penanaman disiplin dilakukan sejak anak usia dini karena pembentukan disiplin dalam mengerjakan tugas memerlukan sebuah proses atau pembiasaan yang dilakukan secara berulang dan konsisten. Konsisten perlu dilakukan dalam hal ini supaya dipercaya anak sehingga anak tahu bahwa disiplin mengerjakan tugas merupakan sikap yang harus dimiliki semua orang jika ingin sukses. Menurut asumsi peneliti mengapa token ekonomi dapat meningkatan kepatuhan pada anak, karena dengan diberiakan token ekonomi membantu motiovasi anak agar dapat lebih rajin dan tidak bermalas-malasan lagi karena anak merasa senang dan termotivasi untuk mendapatkan hadiah atau penghargaan seperti teman-temannya.

\section{KESIMPULAN}

Berdasarkan hasil penelitian yang dilakukan, dapat disimpulkan sebagai berikut :

1. Sebelum diberikan terapi token ekonomi, siswa yang tidak patuh mengerjakan tugas sebanyak 76 orang $(59,8 \%)$ dan setelah diberikan terapi token ekonomi, siswa yang patuh mengerjakan tugas meningkat sebanyak 123orang $(96,9 \%)$.

2. Dari hasil uji statistik didapatkan nilai $\mathrm{p}$ value $=0,000 \quad(\mathrm{p}$ value $<0,05)$ maka dapat disimpulkan bahwa ada terapi token ekonomi efektif untuk meningkatkan kepatuhan mengerjakan tugas pada anak tahap usia sekolah. 


\section{DAFTAR PUSTAKA}

Ahmad. Khaliq. (2011). Identifying Financial Distress Firms: A Case Study of Malaysia's Government Linked Companis.

Anneahira. (2012). Pengertian Pendidikan Tersedia:

http//anneahira.com/artikelpendidikan/.

Azwar, Saifuddin. 2009. Reliabilitas dan Validitas. Yogyakarta: Pustaka Pelajar

Badan Pusat Statistik-RI. (2015). Angka Partisipasi Sekolah (APS) menurut Provinsi. Diakses dari https://www.bps.go.id.

Badan Pusat Statistik Provinsi Riau. (2015). Angka Partisipasi Sekolah (APS) menurut jenjang Pendidikan dan Kabupaten/Kota di Provinsi Riau. Diakses dari https://riau.bps.go.id.

Cluff, Hardcastel. (2011). Public Private. Partnership, Managing Risks And Oportunitles. Osney Mend. Oxford : Blackwells.

Corey, G. (2013). Teori Konseling Dan Pisikoterapi. (Alih Bahasa: E.Koeswara). Bandung: Refika Aditama.

Gunarsa, Singgih D. (2008). Psikologis Anak: Pisikologis Perkembangan Anak dan Remaja. Jakarta : PT.BPK Gunung Mulia.

Djamarah, Syaifudin Bahri. 2012. Psikologi Belajar. Jakarta: Rinkea Cipta

Hamid, Darmadi. (2010).Kemampuan Dasar Mengajar. Bandun: Alfabeta.

Hidayat , A. A. A. (2009). Metode Penelitian keperawatan \&Teknik Analisis.

Hurlock , Elizabeth B. (2009). Perkembangan Anak dan Remaja Jilid 1. Jakarta: Erlangga.

Jhaja. Yudrik. (2011). Psikologi Perkembangan. Jakarta: Kencana.
Keliat., S Daulima., \& Faridah, (2011). Manajemen perawat psikososial \& kader kesehatan jiwa; CMHM intermediet course. Jakarta: EGC.

Keliat., S Daulima., \& Faridah, (2007). Psikologis klinis. Yogyakarta Refia aditama

Khuzaimah, A. 2017.Efektifitas Pengunaan Teknik Tokrn Ekonomi Terhadap Perilaku Prokrastinasi Akademik Mahasiswa di FKIK Universitas Jambi (Tesis). Journal Psycho Idea.

Khonlou. N. Brankin. T (2009). The power of resilience. Jakarta: Universal Indonesia.

Kingsburry,M., Coplan, R.J., \& Rose Krasnor,L. (2013).Shy but Getting BY An Examination in Childhood. Social Development, 22(1),126-145. Doi:10.1111/sode.12003.

Kusuma. Dharma, K. (2011). Metodologi Penelitian Keperawatan. Jakarta: CV. Trans Info.

Kurniawati,Yuli. (2010). Modifikasi Perilaku Anak Usia Dini. Semarang: UNNES

Maman, Ukas. (2004). Manajemen Konsep, Prinsip, dan Aplikasi.Bandung: Agnini.

Martin, G. \& Pear, J. (2009). Behavior Modification. USA: Pearson Eduction.

Mufiddah, Ummu. ( 2012 ). Efektifitas Pemberian Reward Melalui Metode Token Ekonomi Untuk Meningkatkan Kedisiplinan Anak Usia Dini (tesis). (http://journal.unnes.ac.id)

Muriyawati. (2016). Pengaruh pemberian terapi token ekonomi terhadap motivasi belajar siswa sekolah dasar.

(htt://media.publikasi/journal.ac.id)

Moenir. H.A.S. (2013). Manajemen Pelayanan Umum di Indonesia. Jakarta: Bumi aksara. 
Notoatmodjo, S. (2012). Metode Penelitian Kesehatan. Jakarta: Rineka Cipta.

Notoatmodjo. S. (2010). Metode Penelitian Kesehatan. Jakarta: Rineka Cipta.

Potter. Perry, (2009). Fundamental For Nursing, Buku 1,Edisi : 7. Jakarta: Salemba.

Purwanto. (2012). Metodologi Penelitian Kuantitatif. Yogyakarta: Pustaka Pelajar.

Purwanto . 2015. Evaluasi hasil belajar. Yogyakarta: Pustaka Pelajar.

Rahman. Arif. (2011). Intervensi Cerdas. Jakarta: Gagas Media.

Rahmat, Firlia. (2004). Token Ekonomi. Yogyakarta: Graha Ilmu.

Nyoman, Rohmania. 2016. Penerapan teknik modifikasi perilaku token ekonomi untuk meningatan kedisiplinan anak usia dini. (http://Journal.Formatif.ac.id)

Santrock, J. W. (2007). Human Development:Perkembangan masa hidup. Jakarta: Erlangga.

Slameto. (2013). Belajar dan Faktor-Faktor yang Mempengaruhinya. Jakarta: PT.Rineka cipta

Stuart, G. (2013). Principle and practice of psychiatric nursing (10th ed.). Philadelphia:Mosby.Tucker, $C$. J.,Finkelhor, D., Sattuck,A. M.,\& Turner.

Suryadi. (2006). Model Hubungan Kausal Kesadaran, Pelayanan, Kepatuhan Jakarta: Bumi Aksara.

Suryadi. (2011). Buku Ajar Teknik Disiplin Usia Dini. Jakarta: Erlangga

Sulivan. Eillen. C . ( 2010). Character Education on The Gymnasium: Teaching More than The Physical. Boston University.
Syah. Muhibbin. (2010). Pisikologi Dengan Pendekatan Baru. Bandung: PT.Remaja Rosda Karya.

Tu'u. Tulus. (2004). Peran Disiplin pada Perilaku dan Prestasi Belajar. Jakarta: Grasindo.

Wantah, Maria J. 2005. Perkembangan Disiplin Dan Pembentukan Moral Pada Anak Usia Dini. Jakarta : Depdiknas.

Wirantasa, Umar (2017). Pengaruh Kedisiplinan Siswa Terhadap Prestasi Belajar Matematika (http://Journal.Formatif.ac.id).

World Healty Organization. Global Schoolbased Student Healty Survey (GSHS), Purpose and Methodology;2013.

Wong , Donnal L. (2009). Buku Ajar Keperawatan Pediatric. Vol. 1.Edisi 6. Jakarta: EGC.

Wong, 2011, D. L., Eaton, Wilson,Wingkelstein, \& Schwarts.(2012). Buku Ajar Keperawatan Pediatric Wong (S.K.Andy Hartono, Setiawab, Trans. 6 ed.). Jakarta: EGC.

Widodo, AN. s. (2012). Cerdik menyusun Proposal Penelitian Skripsi, Tesisi. Jakarta: Bumi Aksara.

Yusuf, S. (2010). Pisikologi perkembangan anak dan remaja. Bandung: PT.Remaja Roda Karya.

Yuniarno, Ma'arif. 2016. Peningkatan Motivasi Dan Prestasi Belajar Fiqh Dengan Model Koperative Learning Tipe STAD Di Madrasah. Jurnal Pendidikan Sekolah Dasar Vol. 2, No. 2 Agustus 2016. 